\title{
Use of biofeedback combined with conventional therapy in the swallowing rehabilitation of older adults: an integrative literature review
}

\author{
Everson Hozano da Silva Rodrigues ${ }^{1}$ \\ https://orcid.org/0000-0002-9268-0386 \\ Maria das Graças Wanderley de Sales Coriolano' \\ https://orcid.org/0000-0002-7937-7761 \\ Carla Cabral dos Santos Accioly Lins ${ }^{1}$ \\ https://orcid.org/0000-0002-1018-5331
}

Universidade Federal de Pernambuco UFPE, Recife, Pernambuco, Brasil.

Conflict of interests: Nonexistent

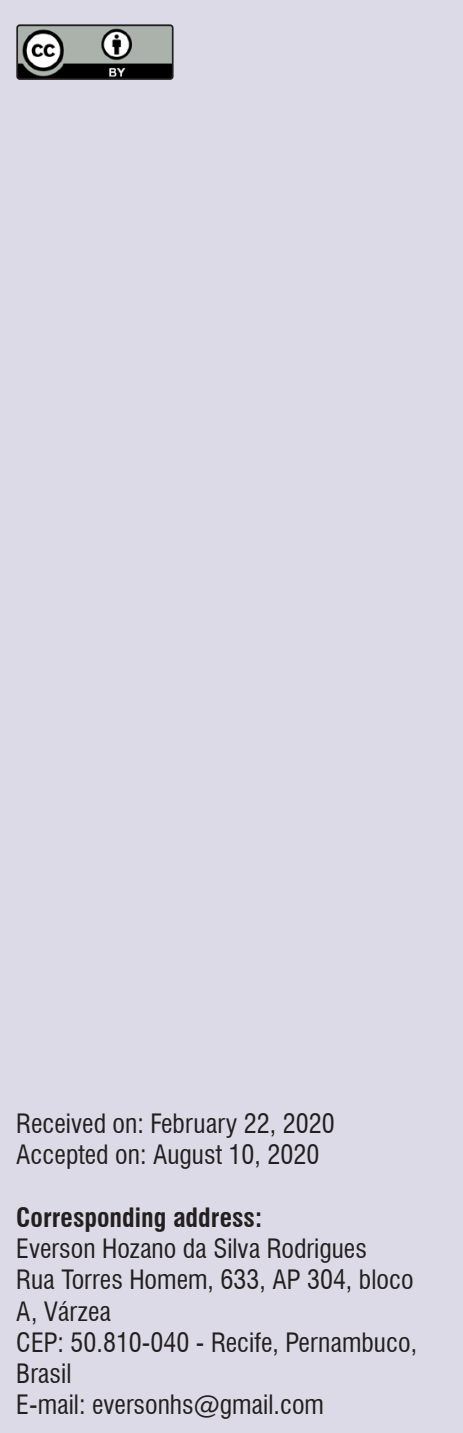

\section{ABSTRACT}

Purpose: to identify biofeedback methods combined with conventional therapy in the swallowing rehabilitation of older adults.

Methods: an integrative literature review that searched the LILACS, MEDLINE/PubMed, BIREME, SciELO, and Scopus databases, with no restrictions of time or language. The search items used were deglutition, biofeedback, elderly, rehabilitation, and their corresponding terms in Portuguese. The articles were evaluated with the adapted Newcastle-Ottawa Scale (NOS).

Results: out of the 73 articles found in the databases, four, with a longitudinal design, were considered eligible. The biofeedback methods described were accelerometry, pressure balloon, and surface electromyography. The swallowing disorders observed were hypofunctioning of articulatory organs, increased oral transit, decreased laryngeal elevation, residues in pyriform sinuses and vallecula, reduced cough reflex, and change in voice quality. Regarding the effectiveness assessment of the recommended technique, a study used the clinical assessment combined with videofluoroscopy, before and after the treatment, two studies used the videofluoroscopy before the treatment and clinical assessment after it, and one study used clinical assessment prior to the treatment and swallowing videoendoscopy after it. As for the assessment of bias risk, one article was classified as low, two as intermediate, and one as high, in terms of risk.

Conclusion: the biofeedback methods combined with conventional therapy to treat dysphagia in older adults were accelerometry, pressure balloon, and surface electromyography, whose use had positive effects.

Keywords: Dysphagia; Rehabilitation; Neurofeedback; Aged 


\section{INTRODUCTION}

The demographic and epidemiologic profile of the world population has been changing in the last decades, posing a great challenge to global public health. The age pattern change is a dynamic process that is taking place worldwide, while the technological advances in medicine are contributing to improve and optimize the losses at the physical and psychic level ${ }^{1-3}$.

The biological and physiological changes due to the natural aging process tend to start when one is 50 years old ${ }^{4}$. In this context, the stomatognathic system's functioning changes both in the structures of which it is made and the functions it performs, including swallowing. In older adults, the changes in this function are considered normal and are characterized by slowed movement and decreased orofacial sensitivity, strength, and mobility of some oral structures. These conditions can aggravate the clinical condition, with complications such as dysphagia associated with malnutrition, dehydration, and risk of bronchoaspiration, potentially leading to frustration and denial when eating, interfering with the older adult's quality of life ${ }^{5}$.

The process of swallowing rehabilitation involves a series of measures, actions, and services aimed at developing or broadening these people's functional capacity and performance ${ }^{1}$, requiring them to perform prolonged and extensive activities. The so-called conventional therapy is commonly used in the professional's day-to-day routine and is based on repetitive isometry myofunctional exercises. Its goal is to increase muscle tone, which is used to improve the mobility and counter-resistance, improving the muscle's physiology. This leads to increasingly limited results, a task that sometimes turns out to be expensive and difficult, besides demanding a great amount of time $e^{6,7}$.

There is a gradual loss of motivation throughout the rehabilitation treatment, as well as a high nonattendance rate on the part of the patients even before the treatment is concluded. This scenario led to the search for new methods to make the activity more interesting and fun, resulting in their greater commitment to the treatment ${ }^{6}$. Among these methods, the biofeedback stands out.

Biofeedback, a term that dates from 1969, reflects the combination of several methodological procedures and learning theories from different fields that arose in the $20^{\text {th }}$ century. The training includes different awareness and relaxation methods, such as muscle, respiratory, and cognitive techniques, which make the self-regulation of the body processes easier. As a therapeutic strategy, it furnishes an immediate return of physiological processes (which the person may not be aware of or may have difficulty controlling), enabling them to learn voluntary regulation of physiological and emotional responses ${ }^{8}$.

Different electronic and mechanical devices are used to reliably measure the various physiological processes through biofeedback. Right after obtaining the data, they are analyzed and fed back for the therapist and patient to consider them as a psychoeducational procedure to strengthen the autonomic and neuromuscular activity. This feedback can be either analogical or digital, either auditory or visual ${ }^{9}$.

Given the above, this study aimed to survey the scientific literature to identify what biofeedback methods are used in combination with conventional therapy in the swallowing rehabilitation of older adults.

\section{METHODS}

This study is an integrative literature review, which makes it possible to search, critically evaluate, and summarize the available evidence on a delimited theme, contributing to the evidence-based health practice. Six methodological stages were followed, namely: 1 - identification of the theme and definition of the research question; 2- the establishment of inclusion and exclusion criteria for the studies; 3- definition of the information to be extracted from the selected studies, and their categorization; 4- evaluation of the studies included in the review; 5- interpretation of the results; 6 - presentation of the review and summary of knowledge ${ }^{10}$.

In the first stage, the investigation motivated the following research question: "What biofeedback methods are used in swallowing rehabilitation in combination with conventional therapy in older adults?". Then, eligibility criteria were defined to obtain and select the articles through search, between November 2018 and January 2019, in the LILACS (Latin American and Caribbean Health Sciences Literature), MEDLINE/ PubMed (United States National Library of Medicine), BIREME (Latin American and Caribbean Center on Health Sciences Information), SciELO (Scientific Electronic Library Online), and Scopus databases.

The search had no language or time restrictions to increase its sensitivity. The terms employed in the search for the studies were identified in the Health Sciences Descriptors (DeCS) and MeSH (Medical Subject Headings), from where the following keywords were selected, along with their respective English 
terms: deglutição (deglutition), biofeedback, idoso (elderly), reabilitação (rehabilitation). The Boolean operators OR and AND were used to combine the terms employed in the search for the publications. The search strategies used for locating the articles in each database are described in Table 1.

Table 1. Search strategies used in the databases

\begin{tabular}{ll}
\hline DATABASE & \multicolumn{1}{c}{ SEARCH STRATEGY } \\
\hline & ("deglutition"[MeSH Terms] OR "deglutition"[All Fields]) AND ("biofeedback, psychology"[MeSH Terms] \\
MEDLINE/PubMed & OR ("biofeedback"[All Fields] AND "psychology"[All Fields]) OR "psychology biofeedback"[All Fields] OR \\
& "biofeedback"[All Fields]) AND ("aged"[MeSH Terms] OR "aged"[All Fields] OR "elderly"[All Fields]) AND \\
& ("rehabilitation"[Subheading] OR "rehabilitation"[All Fields] OR "rehabilitation"[MeSH Terms]) \\
SCOPUS & (TITLE-ABS-KEY (deglutition AND biofeedback AND elderly) \\
BIREME & deglutição OR deglutition AND biofeedback AND idoso OR Elderly AND reabilitação OR rehabilitation \\
SCIELO & deglutição OR deglutition AND biofeedback AND idoso OR Elderly AND reabilitação OR rehabilitation \\
LILACS & Deglutição [Palavras] and Idoso [Palavra] and Biofeedback [Palavra] \\
\hline
\end{tabular}

Review articles were excluded, as well as studies involving animals, studies using other rehabilitation methods in combination with conventional therapy, and studies not approaching the population 60 years old or more.

\section{Data analysis}

The selection took place in two stages: reading the title/abstract and reading the article in full. The first stage was independently carried out by two investigators, based on the inclusion and exclusion criteria, classifying the potentially eligible studies, and dismissing the duplicated ones. In the second stage, the selected articles were read in full. The methodological quality was independently assessed by two reviewers, following the criteria from the Newcastle-Ottawa (NOS) Quality Assessment Scale for Case-Control and Cohort
Studies, of the Ottawa Hospital Research Institute ${ }^{11}$. The NOS scale assesses a study's methodological quality concerning its selection of study groups and the comparativeness between the groups and the results. For each item in the scale, high quality was represented by a star, whereas low quality was not represented by any star.

\section{LITERATURE REVIEW}

Altogether, 73 studies were found in the databases, one of which was repeated. Based on the reading of titles and abstracts, 68 were excluded and five were selected to be read in full. Following the exclusion and inclusion criteria, four articles ${ }^{12-15}$ were selected to comprise the review. The stages that made up the studies' selection process are presented in the flowchart proposed by PRISMA, shown in Figure 1. 


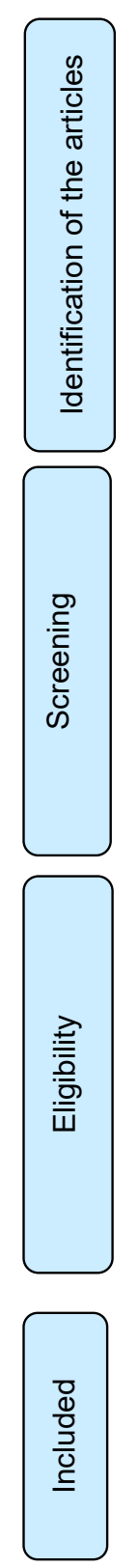

Articles identified by search in the LILACS, MEDILINE/PubMed, BIREME, SciELO, SCOPUS databases $(n=73)$

$$
\text { (1) }
$$




\begin{tabular}{|c|c|c|c|c|}
\hline $\begin{array}{l}\text { Author/year, } \\
\text { country }\end{array}$ & Population of the study & $\begin{array}{l}\text { Assessment } \\
\text { instruments and } \\
\text { treatment }\end{array}$ & $\begin{array}{l}\text { Information used for the } \\
\text { biofeedback }\end{array}$ & Main results \\
\hline $\begin{array}{l}\text { Reddy et al., } \\
2000^{12} \\
\text { United States }\end{array}$ & $\begin{array}{c}4 \text { older adults, of both } \\
\text { sexes, aged } 60 \text { to } 83 \\
\text { years and one } 42 \text {-year-old } \\
\text { woman }\end{array}$ & Videofluoroscopy & $\begin{array}{l}\text { Electrical signal produced } \\
\text { during swallowing. }\end{array}$ & $\begin{array}{c}\text { All the cases studied had an improvement } \\
\text { in laryngeal elevation, confirmed with } \\
\text { videofluoroscopy before and after the } \\
\text { treatment. }\end{array}$ \\
\hline $\begin{array}{l}\text { Félix , Corrêa, } \\
\text { Soares, } 2008^{13} \\
\text { Brazil }\end{array}$ & $\begin{array}{l}4 \text { older adults, of both } \\
\text { sexes, aged } 66 \text { to } 78 \text { years } \\
\text { with Parkinson's disease }\end{array}$ & $\begin{array}{c}\text { O'Neil dysphagia } \\
\text { severity assessment } \\
\text { scale and pressure } \\
\text { balloon biofeedback }\end{array}$ & $\begin{array}{c}\text { Pressure exerted by } \\
\text { suprahyoid musculature } \\
\text { during swallowing with } \\
\text { effort. }\end{array}$ & $\begin{array}{l}\text { At the end of the rehabilitation program, } \\
\text { the liquid and food swallowing pressure } \\
\text { had improved }(p<0.001) \text {. }\end{array}$ \\
\hline $\begin{array}{l}\text { Bogaardt, } \\
\text { Grolman, } \\
\text { Fokkens, } \\
2009^{14} \\
\text { Netherlands }\end{array}$ & $\begin{array}{c}5 \text { older adults, of both } \\
\text { sexes, aged } 64 \text { to } 71 \text { years } \\
\text { and } 6 \text { adults aged } 54 \text { to } \\
59 \text { years, with poststroke } \\
\text { dysphagia. }\end{array}$ & $\begin{array}{l}\text { FOIS scale and surface } \\
\text { electromyography } \\
\text { biofeedback }\end{array}$ & $\begin{array}{l}\text { Electrical signal of the } \\
\text { suprahyoid musculature. }\end{array}$ & $\begin{array}{l}\text { After reassessment with the FOIS scale, } \\
\text { all the participants had an improvement } \\
(p<0.01) \text {, indicating a clinical } \\
\text { improvement in swallowing function, after } \\
\text { using biofeedback in combination with } \\
\text { conventional therapy. }\end{array}$ \\
\hline $\begin{array}{l}\text { Yi Tang et al., } \\
2017^{15} \\
\text { China }\end{array}$ & $\begin{array}{l}103 \text { older adults, of both } \\
\text { sexes, aged } 70 \text { to } 80 \\
\text { years, diagnosed with } \\
\text { Alzheimer's disease. }\end{array}$ & $\begin{array}{l}\text { MNA scale and surface } \\
\text { electromyography } \\
\text { biofeedback }\end{array}$ & $\begin{array}{l}\text { Electrical signal of the } \\
\text { suprahyoid musculature. }\end{array}$ & $\begin{array}{l}\text { Improvement of the swallowing function of } \\
\text { the older adults submitted to conventional } \\
\text { therapy in combination with biofeedback. }\end{array}$ \\
\hline
\end{tabular}

Legend: FOIS: Functional Oral Intake Scale; MNA: Mini-Nutritional Assessment scale.

Figure 2. General characteristics of the articles included in the review

\begin{tabular}{|c|c|c|c|c|}
\hline \multirow{2}{*}{$\begin{array}{l}\text { Items assessed with the } \\
\text { NOS scale }\end{array}$} & \multicolumn{4}{|c|}{ Studies included } \\
\hline & Reddy et al., $2000^{12}$ & $\begin{array}{l}\text { Félix, Corrêa, } \\
\text { Soares, 2008 }\end{array}$ & $\begin{array}{l}\text { Bogaardt, Grolman, } \\
\text { Fokkens, 200914 }\end{array}$ & Yi Tang et al., $2017^{15}$ \\
\hline Definition of the cases & & * & * & * \\
\hline Representativeness & & * & * & * \\
\hline Selection of the controls & & & & * \\
\hline Definition of the controls & & & & * \\
\hline Comparability & & * & * & * \\
\hline Ascertainment of exposure & * & * & * & * \\
\hline \multicolumn{5}{|l|}{$\begin{array}{l}\text { Method of ascertainment for } \\
\text { cases and controls }\end{array}$} \\
\hline Nonresponse rate & & & & \\
\hline
\end{tabular}

Figure 3. Assessment of risk of bias of the studies with the Newcastle-Ottawa Scale (NOS)

The changes in swallowing observed in this group were hypofunctioning of articulatory organs (attributed to their reduced strength, tone, and mobility), decreased elevation of the hyolaryngeal apparatus, and change in cough reflex. The authors performed nine 30-minute therapeutic sessions. The patients were asked to sit on a chair and the speech-language-hearing therapist placed the equipment on the region of the thyroid cartilage. They were then instructed to swallow saliva to calibrate the equipment. In the sequence, they were served foods with varied consistencies. The goal was for the patients to reach the highest graphic signal with their swallowing. Along with this, chin-up and chin-down maneuvers, and Mendelsohn maneuver were used, among other unspecified ones. However, they did not follow rigid criteria regarding the limit of weekly sessions; some patients attended three times, while others, two. This study did not make clear the criteria they used to select the participants of the research, and it did not have a control group either. Hence, it had a high risk of bias on the NOS scale. For the therapy, passive and active maneuvers were used, although it did not clarify which ones they were. The Mendelsohn maneuver was also used along with food swallowing.

In the study that used pressure biofeedback ${ }^{13}$, the authors used the method in four older adults aged 66 to 78 years with Parkinson's disease. The dysphagic changes observed in the study were increased oral transit, food residue in the oral cavity and pharyngeal region, change in post-swallowing voice quality, and 
coughing and/or choking. The therapy lasted two weeks with daily sessions, whose duration was not informed. To administer the biofeedback, a $40 \mathrm{ml}$ air balloon was placed on the neck, on the region of the larynx. The patient was instructed to swallow making effort, viewing a numeric value in the pressure transducer. The goal was to increase this value throughout the sessions. The analysis of the methodological path taken reveals detailed information regarding the choice of the sample, the inclusion and exclusion criteria, and the therapeutic maneuvers. Nevertheless, some points must be considered as a risk of bias, such as the size of the sample and the lack of a control group to determine the efficiency of the therapy adopted.

Two studies used surface electromyography. The authors of the first paper ${ }^{14}$ used the method to treat dysphagia in poststroke patients. Six adults aged 54 to 59 years and older adults aged 64 to 71 years were included in the study. The participants had severe dysphagia; eight of them were on a nasal-enteral feeding tube, while three received restricted food consistencies. The treatment lasted two and a half months on average. For the biofeedback, electrodes were fixed on the region of the suprahyoid musculature. Then, the patient was instructed to keep the larynx elevated (Mendelsohn maneuver), keeping the electromyographic signal constant for eight seconds.

In the fourth study ${ }^{15}$, the use of EMG was analyzed in the treatment of dysphagia in 103 older adults aged 70 to 80 years, diagnosed with Alzheimer's disease. The participants attended daily therapy lasting approximately one hour for four weeks. The biofeedback method made use of electromyography, with electrodes fixed on the submental region. The participants were instructed to perform the Mendelsohn maneuver for two or three seconds, getting simultaneous feedback in the graphic record displayed on the monitor. Based on the NOS scale, this study has a low risk of bias because, besides presenting a well-designed methodology, it counted with a significant sample and a control group to contrast with the tested group.

The literature researched revealed that the biofeedback methods used in combination with conventional therapy to treat dysphagia in older adults were accelerometry ${ }^{12}$, pressure balloon ${ }^{13}$, and surface electromyography ${ }^{14,15}$. All the studies researched ${ }^{12-15}$ observed improvements in the clinical swallowing aspects after using these methods.

Regarding the size of the sample, there was a great divergence between the selected studies. They did not make a sample calculation, which can limit the interpretation and generalization of the results and the conclusion of this review. Furthermore, the samples were selected by convenience and identified in specific services $^{12-15}$, which can generate bias in the selection of the participants. Also, only one study reported having a control group ${ }^{15}$.

Concerning the dysphagia assessment instruments administered in the studies, there was no consensus between the pieces of research. Félix, Correa and Soares $^{13}$ used the O'Neil dysphagia severity scale ${ }^{16}$. One study ${ }^{14}$ used the functional oral intake scale $(\mathrm{FOIS})^{17}$, another ${ }^{15}$, the mini-nutrition assessment scale $^{18}$, while one study did not report the use of any scale before the biofeedback treatment ${ }^{12}$.

As for the time of treatment, the studies did not converge. In the sample of Reddy et al. ${ }^{12}$, the participants had two to three 30-minute sessions a week, although two of them went only once a week. The other study ${ }^{14}$ did not present a clear pattern of days and duration of the sessions. Initially, the participants were attended once a week, and later, every two weeks. It was also proposed to those who could not attend the sessions to do the training at home, but without the biofeedback equipment. This method created an important bias as it did not directly correlate the prognosis with the use of the biofeedback system proposed.

Only the study by Ya Tang et al. ${ }^{15}$ clearly showed how the treatment periods of the participating groups took place. Each person was followed up for four weeks with daily 60-minute therapy sessions. Félix, Correa and Soares ${ }^{13}$ reported that the therapy sessions were carried out daily (except for Saturdays and Sundays) throughout two weeks.

Reddy et al. ${ }^{12}$ used accelerometry as a swallowing rehabilitation method. All the cases studied revealed an improvement in laryngeal elevation with the use of this instrument in combination with conventional therapy, confirmed with videofluoroscopy. This technique enables the acceleration of moving objects to be measured along reference axes. It has been used to assess human movement and, when combined with time measurement, it makes it possible to obtain data on movement and speed. When placed at the level of the cricoid cartilage, it furnishes a tracing recorded in combination with the movement of the larynx during swallowing. When there are no swallowing alterations, the tracing produced by the accelerometer usually presents two opposite polarity peaks. The first peak 
corresponds to the beginning of the laryngeal elevation movement, while the second one refers to the beginning of its lowering movement. The interval between the two peaks corresponds to the period necessary for the elevation, stabilization, and conclusion of the laryngeal muscles ${ }^{14,19}$. The laryngeal elevation is greatly important during the swallowing process. This anteriorizationrelated movement helps to open the upper esophageal sphincter, making it easier for the bolus to enter the esophagus ${ }^{20}$.

The use of pressure biofeedback ${ }^{13}$ transmits the return of muscle contraction - i.e., the pressure exerted on the probe - with luminous graphs or charts, depending on the model. A pressure transducer is connected to an air-filled bulb; when it is pressed, the change in pressure is picked up by the device and shown in its LCD screen, in kilopascal units $(\mathrm{kPa})$. With this equipment, it is possible to measure the maximum pressure exerted. From a physiological standpoint, the patient can be trained to have better control of the contraction of the muscles that participate in the swallowing process. Hence, they can stimulate more effectively the most impaired areas. The participants in this study had dysphagia due to Parkinson's disease, characterized by slowed swallow triggering, lack of liquid control, leading to premature escape and causing cough reflex and solid food residues in the oral cavity. At the end of the rehabilitation program, an improvement in the liquid and food swallowing pressure was observed.

The purpose of the surface electromyography (EMG) described in two studies ${ }^{14,15}$ is to pick up the muscle electrical potential at rest, maximum isometric contraction, and function. It is an extremely useful tool to observe muscle activation/coactivation in the most varied exercise situations ${ }^{21-24}$. This approach has proved to be very efficient when used in combination with conventional therapy in the treatment of dysphagia in different clinical conditions. Studies have shown that there are improvements in the patients' swallowing function and quality of life ${ }^{25,26}$.

Bogaardt, Grolman and Fokkens ${ }^{14}$ used Mendelsohn maneuver in their samples. Initially, the patients attended the clinic once a week for treatment. As the swallowing function improved, the treatment frequency changed to one session every two weeks. When the patient could not attend the clinic, they were instructed to do the exercises at home, without the equipment, two to three times a day (altogether, 40 to 60 daily repetitions). As a home alternative to the EMG biofeedback, the patients were instructed to place the index finger horizontally on the thyroid region for them to feel the larynx moving.

The study by Yi Tang et al. ${ }^{15}$ presented a more robust method, from the separation of the case and control groups to the dysphagia assessment method, with clinical assessment and complementary image examinations (videofluoroscopy). Throughout the therapy, isometry, isotone, and counter-resistance conventional maneuvers were used in both groups' lips, tongues, and cheeks. Lastly, Mendelsohn maneuver was used in combination with electrostimulation in one group, while in the other one, only Mendelsohn maneuver was used. In the data analysis, it was observed that in the twelfth week of therapy, those who used biofeedback had fewer clinical complications due to dysphagia and improved their swallowing function.

The studies ${ }^{14,15}$ concluded that using EMG as biofeedback has a positive long-term impact on the treatment of patients with Alzheimer's disease and improves the swallowing function in patients with stroke sequelae.

The limitations of this study lie in the few studies found addressing the theme proposed, besides the methodology of most of them presenting important biases, which does not enable a wider generalization of the data found.

\section{CONCLUSIONS}

The biofeedback methods described in the literature in combination with conventional therapy to treat dysphagia in older adults were accelerometry, pressure balloon, and surface electromyography. The studies observed improvements in the clinical aspects of swallowing after using these methods. However, more research needs to be published to have a better protocol to assess the effectiveness of this therapy method.

\section{ACKNOWLEDGMENT}

This study was financed, in part, by the Coordenação de Aperfeiçoamento de Pessoal de Nível Superior Brasil (CAPES) - Finance Code 001. PROAP-CAPES.

\section{REFERENCES}

1. BRASIL, Ministério dos Direitos Humanos. Pessoa Idosa. Disponível em http://www.sdh.gov. br/assuntos/pessoa-idosa/dados-estatisticos. Acessado em 12 de abril de 2018. 
2. Machado AMG. Um debate sobre o envelhecimento populacional e o impacto para o sistema único de saúde (SUS): o perfil de idosos residentes na capital e no interior do estado do rio grande do sul internados em Porto Alegre, 2011-2015 [Monografia]. Porto Alegre (RS): Universidade Federal do Rio Grande do Sul; 2017.

3. Rodrigues AMSM. O medo de envelhecer e o papel do gerontólogo [Monografia]. Lisboa (Portugal): Escola Superior de Educação João de Deus; 2012.

4. Daggett A, Logemann J, Rademaker A, Pauloski B. Laryngeal penetration during deglutition in normal subjects of various ages. Dysphagia. 2006;21(4):270-4.

5. Rocha MAS, Lima MLLT. Caracterização dos distúrbios miofuncionais orofaciais de idosos institucionalizados. Geriatr. Gerontol. 2010;4(1):21-6.

6. Cataldi PCP. Game design e reabilitação: investigação de parâmetros para a concepção e avaliação de jogos para reabilitação de pacientes vítimas de AVE [Dissertação]. Brasília (DF): Universidade de Brasília; 2017.

7. Lohse K, Shirzad N, Verster A, Hodges N, Van der Loos HM. Video games and rehabilitation: using design principles to enhance engagement in physical therapy. J Neurologic Phy. Ther. 2013;37(4):166-75.

8. McKee MG. Biofeedback: an overview in the context of heart-brain medicine. Cleve Clin $\mathrm{J}$ Med. 2008;75(2):31-4.

9. Schwartz M, Andrasik F. Evaluating research in clinical biofeedback. In: Schwartz MS, Andrasik F (eds). Biofeedback: a practitioner's guide (3 ed.). New York: Guilford Press, 2003. p. 867-80.

10. Mendes KDS, Silveira RCCP, Galvão CM. Revisão integrativa: método de pesquisa para incorporação de evidências na saúde e na enfermagem. Texto \& Contexto Enferm. 2008;17(4):758-64.

11. Wells GA, Shea B, O'Connell D, Peterson J, Welch $\mathrm{V}$, Losos M et al. The Newcastle-Ottawa Scale (NOS) for assessing the quality of nonrandomised studies in meta-analyses. Ottawa Health Research Institute. Accessed on 02/Mai/2004. Disponible at: http:// www.ohri.ca/programs/clinical_epidemiology/ oxford.htm

12. Reddy NP, Denise LS, Vineet G, Gary EM, Jody C, Amitava D et al. Biofeedback therapy using accelerometry for treating dysphagic patients with poor laryngeal elevation: case studies. J Rehabil Res Dev. 2000;37(3):361-7.

13. Felix VN, Corrêa SMA, Soares RJ. A therapeutic maneuver for oropharyngeal dysphagia in patients with Parkinson's disease. Clinics. 2008;63(5):661-6.

14. Bogaardt HCA, Grolman W, Fokkens WJ. Biofeedback in the treatment of chronic dysphagia in stroke patients. Folia Phoniatr Logop. 2009;61(4):200-5.

15. Tang $Y$, Lin $X$, Lin Xiao-juan, Zheng $W$, Zheng Zhi-kai, Lin Zhao-min et al. Therapeutic efficacy of neuromuscular electrical stimulation and electromyographic biofeedback on Alzheimer's disease patients with dysphagia. Medicine. 2017;96(36): 1-5.

16. O'Neil KH, Purdy M, Falk J, Gallo L. The Dysphagia Outcome and Severity Scale. Dysphagia. 1999;14(3):139-45.

17. Crary MA, Mann GD, Groher ME. Initial psychometric assessment of a functional oral intake scale for dysphagia in stroke patients. Arch Phys Med Rehab. 2005;86(8):1516-20.

18. Guigoz Y, Vellas B, Garry PJ. Mini nutritional assessment: a practical assessment tool for grading the nutritional state of elderly patients. Facts and Research in Gerontology. 1994;(suppl2):15-59.

19. Shephard RJ. Physical activity and optimal health: the challenge to epidemiology. In: Shephard RJ, Tudor-Locke C. The objective monitoring of physical activity: contributions of accelerometry to epidemiology, exercise science and rehabilitation. Toronto: Springer, 2016. p. 1-38.

20. SBGG. Deglutição. Disponível em https://sbgg.org. br/espaco-cuidador/degluticao/ Acessado em 08 de maio de 2020.

21. Robbins JA, Logemann JA, Kirshener HS. Swallowing and speech production in Parkinson's disease. Ann Neurol. 1986;9(3):283-7.

22. Monteiro D, Coriolano MGWS, Belo LR, Cabral ED, Asano AG, Lins OG. Electromyographic assessment of swallowing different types of clinical disease, Parkinson's on and off phases. Rev. CEFAC. 2015;17(2):409-17.

23. Coriolano MGWS, Belo LR, Carneiro D, Asano AG, Oliveira PJA, Silva DM et al. Swallowing in patients with Parkinson's disease: a surface electromyography study. Dysphagia. 2012;27(4):550-5. 
24. Ide BM. Eletromiografia de superfície - aplicações na fisiologia do exercício. Rev. Acta Brasileira do Movimento Humano. 2012;2(4):60-78.

25. Silva MMA. Biofeedback eletromiográfico como coadjuvante no tratamento das disfagias orofaríngeas em idosos com doença de Parkinson [Tese]. Bauru (SP): Faculdade de Odontologia de Bauru, Universidade de São Paulo; 2014.

26. Freitas GS, Silva G, Mituuti CT, Furkim AM, Busanello-Stella AR, Stefani FM et al. Biofeedback eletromiográfico no tratamento das disfunções orofaciais neurogênicas: revisão sistemática de literatura. Audiol., Commun. Res. 2016;21:e1671. 